\title{
Los movimientos sociales. De la crítica de la modernidad a la denuncia de la globalización
}

\section{The social movements. Of the critic of modernity to the denunciation of the globalizacion}

Jaime PASTOR VERDÚ*

\begin{abstract}
RESUMEN
Los movimientos sociales tienen una muy larga historia pero su tratamiento específico como actores politicos, sociales y culturales es relativamente reciente. Su especificidad como tales respecto de los partidos, grupos de interés u Organizaciones No Gubernamentales ha sido objeto de controversia. No obstante, existe amplio consenso sobre la relevancia que tienen en aquéllos los rasgos de desafio, acción colectiva, conflicto, voluntad de cambio, organización duradera y repertorio de acciones principalmente no convencionales. Todas esas características facilitan la construcción de una identidad colectiva, siempre en proceso de renegociación, basada en la denuncia de alguna injusticia y tratando para ello de cambiar la agenda política y el "sentido común" dominante en, al menos, una esfera de la vida determinada.

Este trabajo presenta un análisis de la evolución de los "nuevos" movimientos sociales y su critica de la Modernidad, de los límites de la politica institucional y del estado del bienestar y, después de los cambios durante la década de los 90 del pasado siglo, una interpretación del desarrollo de "novisimos" movimientos sociales globales en un contexto muy diferente de "globalización" neoliberal y crisis del estado de bienestar.
\end{abstract}

\section{PALABRAS CLAVE}

Acción colectiva, Politica, Cambio de valores, Globalización, Democracia participativa.

* Profesor titular de Ciencia Política. Departamento de Ciencia Politica y de la Administración. Facultad de Ciencias Politicas y Sociologia. UNED. jpastor@poli.uned.es 
Los movimientos sociales. De la crítica de la modernidad a la denuncia de la globalización

\begin{abstract}
The social movements have a very long history but their analysis as cultural, social and political actors is relatively new. Their specificity as different of parties, interest groups or Non Governmental Organisations has been very controverted. Nevertheless, there is a large consensus on the relevance, among these movements, of the features of challenge, collective action, conflict, will of change, lasting organisation and repertory of actions mainly unconventional. All these traits help to build a collective identity, always in process of renegotiation, based in the denunciation of some injustice and trying to change the political agenda and the dominant "common sense", at least, in some sphere of the life.

This paper offers an analysis of the evolution of the "new" social movements and their critique of Modernity, the institutional politics and the welfare state and, after the changes in the nineties of the past century, an interpretation of the development of "very new" global social movements in a very different context of neoliberal "globalisation" and crisis of the welfare state.
\end{abstract}

\title{
KEY WORDS
}

Colective action, Politics, Changing values, Globalisation, Participative democracy. 
La historia de los movimientos sociales es muy larga y no es objeto de este trabajo hacer un recordatorio de sus orígenes y enorme diversidad. No obstante, sí es necesario recordar que el interés mostrado por las ciencias sociales hacia los mismos como actores colectivos relevantes, y no simplemente como expresión de "comportamientos anómicos", es relativamente tardio. En realidad, ha sido desde finales de la década de los 60 del pasado siglo, coincidiendo con la emergencia de lo que se ha dado en llamar "nuevos movimientos sociales", cuando se ha ido configurando una amplia comunidad de investigadores de este área. En la actualidad se puede asegurar ya que los resultados de sus trabajos ofrecen una enorme riqueza de teorias, enfoques y estudios de casos que sería imposible resumir aquí.

\section{I. ¿QUÉ ES UN MOVIMIENTO SOCIAL?}

Una primera tarea importante en este campo ha sido el esfuerzo por ofrecer una definición de "movimientos sociales" que ayudara a resaltar su singularidad y, al mismo tiempo, los distinguiera de otros actores colectivos, ya sean partidos políticos, grupos de interés u Organizaciones No Gubernamentales. Así, podemos remitirnos a una ya vieja fórmula recogida por Charles Tilly (1984), según la cual son "una prolongada serie de interacciones entre quienes ostentan el poder y personas que reclaman con éxito hablar en nombre de sectores que carecen de representación formal, en el curso de la cual esas personas hacen públicamente visibles demandas de cambios en la distribución o ejercicio del poder, y justifican esas demandas con manifestaciones públicas de apoyo"; o también a una reciente de Pedro Ibarra, Ricard Gomà y Salvador Martí (2002), para quienes se trata de "un actor político colectivo de carácter movilizador que persigue objetivos de cambio a través de acciones -generalmente no convencionales- y que por ello actúa con cierta continuidad a través de un alto nivel de integración simbólica y un bajo nivel de especificación de roles, a la vez que se nutre de formas de organización variables"); o, en fin, a la de Sidney Tarrow (1998), el cual los describe como aquellos "desafios colectivos planteados por personas que comparten objetivos comunes y solidaridad en una interacción mantenida con las elites, los oponentes y las autoridades"). En estas y otras definiciones coincidirian los rasgos de desafio, acción colectiva, conflicto, cambio, organización duradera y formas de acción principalmente no convencionales para determinar la especificidad de unos actores cuya identidad colectiva no sería el punto de partida sino, más bien, el de llegada -y siempre en reconstrucción- a medida que se genera un "consenso de trabajo en común", no incompatible con su diversidad. A todo esto se suma la necesidad de que esos movimientos tengan como propósito compartido la denuncia de uno $\mathbf{u}$ otro marco de injusticia que pueda verse manifestada en los espacios públicos (de ahí que hayan tendido históricamente en muchos casos a ampliar esa esfera pública introduciendo nuevos temas considerados hasta entonces como "privados"). Es así como los movimientos sociales se han ido construyendo social, politica y culturalmente como agentes de expansión de lo posible $\mathrm{y}$, por tanto, con voluntad de modificar las agendas politicas y las creencias colectivas 0 el "sentido común" dominantes.

Partiendo de esa especificidad compleja se puede distinguir más fácilmente un movimiento social de otros actores politicos y sociales, como los partidos, los grupos de interés y de presión o las ONG, aunque no siempre las fronteras sean claras en la práctica. Así, los parti- 
dos se caracterizan generalmente por ofrecer programas globales orientados principalmente al acceso y al ejercicio del poder político, privilegiando por tanto el ámbito electoral e institucional; los grupos de presión se formalizan con el propósito de influir en el sistema político para la defensa de los intereses de sectores sociales determinados y recurren generalmente a formas de participación convencionales; y las $\mathrm{ONG}$, si bien en muchos casos colaboran o participan en acciones colectivas de protesta o de presión, buscan preferentemente poner en práctica propuestas y proyectos relacionados con los fines altruistas que suelen postular.

Una vez establecidas estas distinciones, la clasificación de los movimientos sociales puede ser también muy variada. Se suele considerar "viejos movimientos sociales" a aquéllos que, como el movimiento obrero, el campesino o los de liberación nacional, han tenido que ver con lineas de fractura que surgieron simultáneamente al desarrollo del capitalismo y a la formación de un sistema de Estados. Estas tenían que ver con la contradicción entre capital y trabajo, con el proceso de industrialización y la desestructuración del campo o con las relaciones jerárquicas o de dependencia entre Estados y naciones. "Nuevos" movimientos sociales, como se ha indicado antes, son principalmente los que surgen en el marco de la crisis de la Modernidad y del paso a primer plano de nuevas contradicciones, como es el caso del movimiento feminista -denunciando las relaciones desiguales ligadas a un sistema de dominación patriarcal-, el ecologista -alertando frente a las consecuencias del industrialismo y del "produccionismo" en el conjunto de la biosfera- o el pacifista -rechazando la dinámica de militarización del planeta en la era nuclear. Finalmente, se ha dado en denominar "novísimos" movimientos sociales a aquéllos asociados a la crítica de la "globalización" a partir de mediados de la década de los 90, adoptando en este caso un carácter multidimensional y por ello definidos también como un "movimiento de movimientos". Obviamente, también cabe hablar de "contramovimientos sociales”, entendiendo por tales aquéllos que desarrollan acciones colectivas destinadas a impedir y oponerse a los cambios y a las demandas procedentes de diferentes movimientos sociales.

Existen también otros movimientos cuya ubicación en la clasificación anterior es aleatoria en función de cuáles sean las demandas o las protestas que generen su acción colectiva: Los movimientos vecinales pueden responder a problemas relacionados con las condiciones de vida de la clase trabajadora (vivienda, transporte...), a determinados proyectos que afectan directamente a su espacio local (en estos casos se les define como movimientos "nimby" ("not in my backyard", no en mi patio trasero)) o, en cambio, con "contramovimientos" de tipo racista o ligados a la exigencia de mayores controles y restricciones de libertades para determinados grupos sociales en los espacios urbanos públicos desde una concepción reduccionista de la "seguridad". Los movimientos estudiantiles, de carácter más espasmódico debido a la renovación periódica que se produce en su medio, tienen que ver generalmente más con los "nuevos" movimientos sociales pero otras veces pueden adoptar las formas de un sindicato tradicional. Los movimientos "okupas" y de solidaridad internacional tienden, por el contrario, a compartir rasgos tanto de los "nuevos" como de los "novísimos" movimientos sociales. Los movimientos de inmigrantes, en fin, comparten rasgos del viejo movimiento obrero (lucha por una jornada laboral y un salario dignos...) con otros de carácter político o cultural o 
de denuncia de la fractura Norte-Sur que tienden a insertarles dentro de los "novísimos" movimientos sociales.

En este trabajo nos vamos a centrar principalmente en el desarrollo de los "nuevos" y "novísimos" movimientos sociales en el marco de la evolución de los Estados de bienestar y de la posterior crisis que les ha ido afectando, especialmente en el contexto europeo.

\section{CRÍTICA DE LA MODERNIDAD Y DE LA POLÍTICA INSTITUCIONAL Y CAMBIO DE VALORES}

Es sin duda en el año 1968 donde podemos situar el punto de inflexión fundamental en el cambio que se produce en nuestras sociedades respecto al periodo que se había abierto tras el final de la Segunda Guerra Mundial hasta el punto que Immanuel Wallerstein (1993) definió lo ocurrido durante ese año como una "revolución en el sistema-mundo". En todo caso, fue evidente que en ese mitificado año se produjo una revuelta juvenil mundial que tuvo su punto más alto de conflictividad en Francia y que se convirtió en experiencia fundadora de una nueva generación politica y cultural durante las décadas siguientes.

Los movimientos que se van configurando a partir de entonces han sido interpretados desde diferentes enfoques, no necesariamente contradictorios, pero aquí nos centraremos en dos: el que los analiza como una critica de la Modernidad y de los limites de la politica institucional, y el que los considera expresión de un cambio de valores.

Según el primero, caracterizado como estructuralista, estos movimientos aparecen como respuesta a "tres aspectos interrelacionados de las sociedades industriales avanzadas capitalistas"
(Offe, 1988): en primer lugar, la agravación de los efectos colaterales negativos de las formas que adopta la racionalidad económica y política y que no afectan sólo a una clase especifica; en segundo lugar, la profundización de los métodos y los efectos de la dominación y el control social (o "colonización del mundo de vida", como la llama Habermas); y en tercer lugar, la pérdida de capacidad autocorrectiva por parte de las instituciones políticas y económicas. En ese sentido, los "nuevos" movimientos, siguiendo de nuevo a Offe, expresarian una critica de los efectos perversos de la modernización que afectan al conjunto de la ciudadanía y no sólo a una clase determinada. Por eso mismo esos movimientos, a diferencia del movimiento obrero, como sostiene Melucci (1986), "luchan no sólo por la reapropiación de la estructura material de la producción sino también por el control colectivo del tiempo, del espacio y de las relaciones de la vida cotidiana”.

Con ese enfoque coincidieron en lo fundamental los análisis realizados por Anthony Giddens (1993), quien subrayaba cuatro rasgos fundamentales de la Modernidad: el capitalismo (entendido como acumulación de capital en el contexto de mercados competitivos de trabajo y de productos), el industrialismo (que conduce a la transformación de la naturaleza y a modificaciones en el medio ambiente), la "surveillance" o control de la información y la supervisión social (a través de instituciones estatales y paraestatales) y el poder militar (basado en el control de los medios para ejercer la violencia en el marco de la industrialización de la guerra). Frente a estas cuatro dimensiones responderían diferentes tipos de movimientos sociales: el movimiento obrero, el nuevo movimiento ecologista, los movimientos a favor de derechos democráticos (incluidos los de las minorias nacionales), el nuevo movi- 
miento por la paz y, por último, de forma transversal a todas esas dimensiones, el movimiento feminista. Todos ellos se habrian convertido en movimientos de carácter estructural y no meramente coyunturales, ya que independientemente de sus fases de latencia o de visibilidad se han constituido como actores colectivos duraderos capaces de desafiar uno u otro pilar de la Modernidad.

Dejando aparte a los sindicatos, esos movimientos han tendido a cuestionar los limites de la politica institucional, tratando de crear nuevos espacios en los que las viejas esferas politicas y no-politicas de la vida social puedan fusionarse. De ahi que haya factores más especificos que explican su desarrollo en determinadas sociedades industrialmente avanzadas: más concretamente, la crisis del Estado de bienestar, del neocorporatismo y del sistema de partidos. En el momento de mayor auge de estos movimientos, a mediados de los años 80, se llegó a sostener que se había agotado el "viejo paradigma político" de la postguerra, basado en el crecimiento económico, la distribución y la seguridad, como conjunto de valores compartidos por las sociedades industrialmente avanzadas y asumidos por partidos y grupos de presión. Frente a ellos emergería un nuevo paradigma, el del "modo de vida", el cual opondria la "supervivencia" al "progreso" y facilitaría la aparición de nuevos contenidos, nuevos temas y nuevos actores en la vida politica. Corolario de esa nueva linea de fractura sería la aparición de los partidos verdes, con el Partido Verde alemán como principal referente, y también la tendencia del resto de partidos a incluir en su agenda y programa respuestas a esta problemática.

De esta forma, el mismo desarrollo alcanzado por el Estado de bienestar, mediante los éxitos logrados en la satisfacción de una serie de necesidades materiales, habría favorecido la crítica del modelo de crecimiento económico en que se ha basado, permitiendo que una parte significativa de la ciudadanía pusiera decididamente el acento en la "calidad de vida", en el derecho a la igualdad en todos los planos o en la defensa del medio ambiente, víctima en muchos casos de aquel modelo.

Una explicación similar se puede aplicar a los efectos del neocorporatismo. Este habria permitido una dinámica de concertación entre los grandes grupos de presión (principalmente, patronal y sindicatos) respecto a la distribución de los resultados de ese crecimiento económico, limitándose a discutir el "cuánto" y no el "por qué", el "cómo" y el "para quién" de esa distribución, marginando así a amplios sectores de la población que no se sienten representados en esos grupos y no teniendo en cuenta, por tanto, los efectos colaterales negativos de esos acuerdos.

En cuanto a los partidos, éstos habrían conocido un profundo proceso de "des-radicalización" ideológica, desactivación de la militancia de base y erosión de la identidad colectiva, perdiendo así en parte su posición mediadora, fuera de los períodos electorales, entre el capitalismo y los grandes problemas políticos que preocupan a la ciudadanía. De esta forma, la tendencia generalizada hacia unos partidos "atrápalo-todo" se volvería en contra de su capacidad para impedir que sus propios electores recurran o apoyen otros medios de acción politica no institucional cuando no están de acuerdo con determinadas decisiones politicas que puedan afectarles directa 0 indirectamente. Se reflejaría así esa tensión creciente entre los resultados electorales y los conflictos que surgen en torno a decisiones politicas concretas, relacionada en realidad con la diferencia entre legitimidad de origen y legitimidad 
de ejercicio de los gobiernos, acabando ésta última por ser cuestionada muchas veces debido a la distancia entre las promesas electorales de los partidos y las politicas concretas que desarrollan desde el poder. Es todo ese proceso el que habría estado perjudicando particularmente a los partidos socialdemócratas y eurocomunistas, si bien de manera desigual según los países y las particularidades respectivas, pero también a los partidos de derechas o de tipo populista.

Dentro de este enfoque estructural se parte además de que la base social de esos movimientos es plural, si bien se comprueba que sus núcleos principalmente activos se encuentran más en la "nueva clase media" o en los también llamados "grupos de frontera", precisamente porque por los recursos económicos, culturales y de tiempo libre con que cuentan son las capas potencialmente más sensibles y más disponibles para actuar politicamente. Conviene aclarar que por "nueva clase media" habria que entender, desde este punto de vista, no sólo los profesionales sino también un amplio sector de empleados estables relacionados con los servicios sociales. Pero también entre los sectores "periféricos" (mujeres, jóvenes, estudiantes) es fácil observar una notable presencia en esos movimientos, siendo en cambio mucho menor la de la clase trabajadora ocupada en el sector privado.

Desde el enfoque psicológico o cultural se ha puesto el acento en la influencia del cambio de valores en determinadas capas sociales de las sociedades occidentales, sin proponer por ello un determinismo cultural que fuera alternativo al peso de factores de orden económico o político. Así, Ronald Inglehart (1977 y 1991) reconoce que las fuentes de ese cambio se sitúan en la prosperidad económica alcanzada por las sociedades occidentales desde la Segunda
Guerra Mundial y en la ausencia de guerra total. Han sido precisamente esos logros los que han permitido que determinados sectores de la población hayan podido pasar a poner el énfasis en otro tipo de necesidades (calidad de vida), más allá de las básicas. En ello han influido también la expansión de la educación secundaria y superior, la innovación tecnológica y los cambios en la estructura ocupacional o el papel de los medios de comunicación, favoreciendo todo ello el reemplazo intergeneracional que se ha ido produciendo y que explica que las potenciales "contraélites" estén más distribuidas que antes en el conjunto social.

Todo lo anterior habría facilitado, según Inglehart, que desde finales de los años 60 se desarrollaran tanto la tendencia a la polarización de la población en torno a las dimensiones "materialista" y "postmaterialista" como el lento y desigual, pero muy real, incremento de esta última dimensión en nuestras sociedades, debido a que la nueva generación nacida en la postguerra asumió en su juventud un cambio de valores al que no ha renunciado, al menos mayoritariamente, cuando se ha hecho adulta. Esto, a su vez, favorece que las siguientes cohortes de edad puedan ser socializadas en ese cambio.

Este proceso tiene consecuencias evidentes en el ámbito político, ya que ayuda a explicar los cambios que se están produciendo en las bases sociales de la política, en el grado de apoyo dado a las instituciones y en el cambio de estilo en la participación politica: aumentan las actividades "desafiadoras de las elites" frente a las "dirigidas por elites" y, por lo tanto, puede ocurrir lo mismo con la política no institucional frente a la institucional.

Tendríamos así un contraste notable 
entre, por un lado, el aumento de la "competencia politica subjetiva" de una parte creciente de la ciudadanía, y por otro, el descenso de la capacidad de las instituciones politicas para canalizar esa competencia. De ahí deriva el desarrollo de formas de participación política no convencional, a través particularmente de los movimientos y grupos ad hoc, ya que en ellos es más fácil expresar las preferencias individuales con mayor precisión y exigiendo cambios en políticas especificas. Por eso mismo el hecho de que disminuya la participación electoral en distintos países no desmiente ese análisis sino que lo confirma, ya que el voto aparece como una forma de participación "dirigida por elites".

Todo esto no significa sostener que los "postmaterialistas" sean mayoria en nuestras sociedades, ya que siguen siendo una minoría. Pero, a pesar de ello, dada su posición estratégica en la sociedad (al encontrarse entre los de alto nivel educativo, ser politicamente más activos y tener capacidad de incidencia en la opinión pública y en algunos medios de comunicación), su influencia en la agenda politica puede ser muy superior a su reducido peso numérico.

Tiene interés también mencionar la clasificación que establecía Inglehart de las diversas formas de "movilización cognitiva" ante la politica. Así, cabría distinguir los "apolíticos", los "militantes dirigidos por elites", los "militantes cognitivamente movilizados" y los "no militantes cognitivamente movilizados". La tendencia previsible sería, según las encuestas de opinión, la de un declive en las filas de los "militantes dirigidos por elites" (con lo cual se erosionará la base de apoyo a los partidos establecidos), mientras que aumentaría el modelo de "militantes cognitivamente movilizados" (es decir, de aquéllos que mantendrian una lealtad sólo condicional a los partidos establecidos y que serian base potencial para la consolidación de nuevos partidos). De éstos últimos y de los "no militantes cognitivamente movilizados" extraerían su apoyo los nuevos movimientos sociales, los cuales serian portadores de una nueva cultura politica: en ellos se da menos importancia al crecimiento económico y más a la calidad de vida, no identificada sólo con lo económico; se pide más participación política y se buscan relaciones menos jerarquizadas y más informales que hagan compatibles la autonomia personal y la solidaridad.

Ha habido muchas criticas a la teoría elaborada por Inglehart que merece la pena mencionar. Empezando por el título de su primera obra, La revolución silenciosa, ya que parecía crear cierta ilusión en un proceso gradual de cambio que tiende, por un lado, a sobreestimar el peso de los sectores portadores de valores postmaterialistas y, por otro, a subestimar las respuestas que desde el "materialismo" y desde una "nueva derecha" están surgiendo y que han llegado a generar "contramovimientos sociales" (racismo, antiaborto, "mayoría moral", nacionalismos agresivos...) o, simplemente, la reprivatización de algunas cuestiones que habian pasado al ámbito público, como reflejo de la contraofensiva neoconservadora. En resumen, faltaría resaltar más la contradicción entre la intensidad preferencial de determinadas minorias sociales, con tendencia a polarizarse entre ellas, por un lado, y la apatía de una mayoría, por otro.

Otros colegas proponen sustituir la definición como "postmaterialistas" de esos valores por la de "postconsumistas" (Riechmann, 1991) o por "necesidades postadquisitivas" (Alonso, 1994)), ya que precisan más claramente lo que pretenden cuestionar y evitan una confusa polarización entre la preocupación por la 
satisfacción de las necesidades básicas (materialismo) y la aspiración a que su logro esté ligado no sólo a lo cuantitativo sino también a la búsqueda de otra "calidad de vida" o "modo de vida", no subordinado al mercado. Estas observaciones son importantes, ya que ayudan a entender por qué el apoyo a esos valores se da más entre quienes se identifican con la izquierda que entre los que lo hacen con la derecha.

Esa posibilidad de articular la lucha por la "calidad de vida" con el énfasis que desde la izquierda se pone en la justicia social ha sido también interpretada desde el marxismo como una expresión de las nuevas necesidades y demandas de los trabajadores como seres humanos $y$, por tanto, de su lucha contra su alineación como tales, además de la que emprenden contra la explotación. Así, en palabras de Michael Lebowitz (2005), "en lugar de una oposición inherente entre los 'nuevos movimientos sociales' y la lucha de los trabajadores como una clase contra el capital, debe considerarse a los nuevos movimientos como la expresión de otras necesidades de los trabajadores y como el desarrollo de nuevos centros de organización de la clase obrera, funcionando 'en el amplio interés de su emancipación'. Y en la medida en que estas luchas estén dirigidas contra la posición del capital como dueño de los productos del trabajo social, tales luchas ofrecen la posibilidad de agrupar (en lugar de mantener separados) a todos aquéllos que no tienen nada que vender más que su fuerza de trabajo".

Pero, aun introduciendo estas y otras matizaciones, lo que importa resaltar es que ese cambio de valores es una tendencia que actúa en nuestras sociedades, contribuyendo así a modificar la actitud de la opinión pública ante muchas cuestiones centrales de la vida política y obligando a tener en cuenta esta nueva dimensión a la hora de analizar el comportamiento electoral. En el caso español también hemos podido comprobar que se puede aplicar esta nueva dimensión, si bien el porcentaje de "postmaterialistas" es menor que en la mayoría de países occidentales.

Conviene precisar que si bien nos estamos refiriendo fundamentalmente a determinada área geo-económica y cultural, estos "nuevos" movimientos han ido conociendo una extensión creciente a otras partes del planeta debido precisamente a que también en ellas se manifiestan las distintas dimensiones institucionales de una Modernidad cuyas consecuencias negativas se extienden a escala planetaria. En esos otros casos, junto con las reducidas capas con capital cultural crítico los sectores que se implican en movimientos como el ecologista se encontrarian entre la población principalmente campesina.

\section{III.CRÍTICA DE LA “GLOBALIZACIÓN" Y DEFENSA DE "LO COMÚN"}

La relativa desmovilización que sigue al ciclo intenso de protestas del movimiento eco-pacifista contra la instalación de cohetes nucleares en territorio europeo (y que en nuestro caso llega hasta 1986 con el referéndum de la OTAN y la derrota del No) y, sobre todo, la posterior caída del muro de Berlín en 1991 darán paso a una nueva fase histórica, definida convencionalmente como "globalización", la cual se produce bajo la hegemonía de un paradigma neoliberal que ha ido teniendo efectos cada vez más visibles en la crisis del "modelo" que criticaban los nuevos movimientos sociales, pero con una salida muy distinta a aquélla por la que éstos luchaban.

Así, en lugar de ir "más allá del Estado de bienestar" y de avanzar hacia un 
"mejor vivir", se ha ido produciendo un retroceso hacia "Estados del malestar" y un "vivir peor" que pretenden cuestionar las conquistas sociales y culturales de la postguerra. Este nuevo contexto, unido a la crisis de credibilidad de las alternativas al capitalismo, provoca una crisis de estos movimientos y una fragmentación de los sectores sociales en los que se habían apoyado, ya que la preocupación por la seguridad social y material vuelve a pasar a primer plano y la discrepancia entre los valores "postmateriales" abstractamente compartidos y su aplicación en la vida cotidiana se hace cada vez más visible.

Es precisamente en esa transición desde finales de los 80 hasta mediados de los 90 cuando se percibe un verdadero auge de las ONG en tanto que doble respuesta tanto a la crisis del Estado de bienestar y a la agravación de la fractura Norte-Sur como a la crisis de perspectivas de las principales redes animadoras de los movimientos sociales alternativos y antisistémicos: de la protesta se tiende a pasar no sólo a la propuesta de alternativas sino también a la gestión de proyectos asistenciales o de desarrollo que, sin embargo, necesitan contar con la ayuda de los gobiernos o el mecenazgo de empresas privadas hipotecando así su autonomía y, con ello, la vocación de erradicar las causas de las injusticias que muchas de esas ONG denuncian. Esas contradicciones se han acentuado en muchas ONG durante los años 90 en el marco de lo que se ha definido como "intervencionismo humanitario" por parte de la OTAN, de grandes potencias o de la propia ONU a partir de crisis como las de Ruanda o la ex-Yugoslavia. Tensiones similares se desarrollan en el denominado "Tercer Sector", el cual aspira a moverse entre unos Estados menguantes en lo social, por un lado, y el creciente proceso de remercantilización de bienes públicos, por otro (Gómez Gil, 2004).
Pero la fase triunfalista de los discursos del "fin de la historia" y de la "globalización feliz" se verá pronto sucedida por otra en la que los efectos negativos de la misma irán generando nuevas resistencias y, con ellas, las primeras redes madrugadoras de lo que se ha dado en llamar movimientos "antiglobalización” pero que sería más adecuado definirlos como "movimientos por la justicia global" ya que aspirarán a ir articulando las luchas contra los diversos marcos de injusticia que se manifiestan a escala planetaria dentro de un discurso común.

En efecto, se trata ahora de un nuevo activismo transnacional y alternativo frente al peso creciente que está teniendo la concentración de poder económico en las grandes empresas transnacionales así como al nuevo protagonismo de las Instituciones Financieras Internacionales (FMI, BM) y, más tarde, la Organización Mundial del Comercio (OMC). Las primeras acciones de protesta, con ocasión de la celebración de las Cumbres de esas instituciones o del G-8, serán calificadas como una "nube de mosquitos" o un "enjambre" de un nomadismo militante que confluye con el primer desafio simbólico relevante, el levantamiento zapatista del 1 de enero de 1994, coincidiendo con la entrada en vigor del Tratado de Libre Comercio de América del Norte entre EEUU, México y Canadá. Es a partir de entonces cuando vemos extenderse, discreta pero gradualmente y principalmente entre la juventud, redes transnacionales de activistas, contando esta vez con la ayuda inestimable de las nuevas tecnologías de la información y de la comunicación.

Más tarde, es la paralización del proyecto de Acuerdo Multilateral de Inversiones (AMI), desvelado y denunciado por la publicación mensual Le Monde Diplomatique en 1998, la que se convierte en 
una primera victoria parcial que contribuirá a la creación de una red internacional (Asociación para una Tasación sobre las Transacciones Financieras, ATTAC) especialmente dedicada a la denuncia de la "globalización financiera".

Es sin embargo la movilización ante la Cumbre de la OMC en Seattle a finales de noviembre de 1999 la que marca el inicio de un ciclo ascendente de luchas que tendrá finalmente el 15 de febrero de 2003 su cenit o momento culminante. Es en esa ciudad estadounidense donde la protesta refleja la confluencia de muy diversos sectores sociales y organizaciones en torno al eslogan "El mundo no es una mercancía" y al bloqueo de una reunión de jefes de estado y de gobierno que concluye finalmente en un fracaso. De ahí que la lección que extraen muchos activistas a partir de entonces es que "Sí, se puede"...resistir al neoliberalismo, convirtiéndose por tanto ese acontecimiento en un estímulo para la rápida extensión de redes e iniciativas de acción en muy distintas partes del mundo, como he tratado de explicar en otros trabajos (2002).

El paso siguiente será principalmente la puesta en pie del Foro Social Mundial de Porto Alegre (referente emblemático de una experiencia de presupuestos participativos que se ha ido extendiendo a muchos municipios en muy diversos paises) a partir de enero de 2001, alrededor del eslogan "Otro mundo es posible", como alternativa frente al Foro Económico de Davos. Luego, veremos un momento especialmente crítico en el devenir de estos movimientos, tras los atentados del 11-S de 2001 y la apertura de un nuevo escenario de "guerra global permanente", que obliga a éstos a introducir el rechazo a la guerra de Iraq y culmina en la jornada mundial de protesta del $15-\mathrm{F}$ de 2003. Es a partir de entonces cuando se entra en una nueva fase de "sedimenta- ción" en la que la prioridad pasa a ser la consolidación de los espacios de diálogo y coordinación de las diferentes redes que se reconocen en los Foros y los diversos Encuentros que se desarrollan a distintas escalas: local, nacional, estatal, continental y mundial (Calle, 2006). El reconocimiento de la necesidad de llegar a los distintos continentes ha conducido, finalmente, a una nueva etapa en la que se ha optado por la celebración de un Foro Mundial policéntrico en el año 2006 en Caracas, Bamako y Karachi.

Si nos referimos al marco europeo, la evolución de estos movimientos se ha reflejado en el desarrollo de Foros Sociales periódicos y en la ampliación creciente en ellos de una temática que tiende en este caso a poner mayor énfasis en la cuestión social, en el rechazo de determinadas directivas de la UE (en particular, la conocida como "directiva Bolkestein" de liberalización de servicios) y en la crítica del proyecto de Tratado Constitucional Europeo por considerar que éste contribuye a constitucionalizar el neoliberalismo. Es en Francia, sin duda, donde la confluencia entre las principales redes de estos movimientos y las organizaciones sindicales y sociales ha sido mayor, llegando así a hegemonizar el No que se produjo en el referéndum sobre aquel proyecto de Tratado el 29 de mayo de 2005.

La principal novedad, aun siendo relativa -ya que siempre ha habido precedentes de lo que éstos expresan- de estos movimientos se encuentra en su rasgo común de tratar de ver con "gafas globales" los problemas que tienen que afrontar en el ámbito estatal o local. Su percepción de que muchas de las decisiones que se toman sobrepasan el marco del Estado-nación y se adoptan en instituciones o centros de poder transnacionales 0 interestatales les lleva a querer ser también actores colectivos a esos niveles 
dentro de la nueva esfera pública global que se está configurando.

Esta tendencia se da con mayor razón debido a que la "desafección" hacia las democracias realmente existentes se ha acentuado, incluso allí donde parecían más consolidadas. Así, en un estudio dedicado a los países del "Centro" a finales del siglo XX se aseguraba que "los ciudadanos en la mayoría de las democracias trilaterales están menos satisfechos con la actuación de sus instituciones públicas representativas que hace un cuarto de siglo"; la tendencia a la volatilidad y al escepticismo del electorado ha aumentado, el alineamiento partidario sigue en descenso y en 11 de los 14 países estudiados la confianza en el parlamento también ha bajado (Putnam, Pharr y Dalton, 2000).

De esta forma, la crisis de la democracia representativa a escala nacionalestatal, la del parlamento como sede de un poder efectivamente legislativo y la del sistema de partidos en el que se apoya (con la tendencia al duopolio del "centro" político y a la aparición recurrente de escándalos de corrupción) generan un escepticismo ciudadano respecto a la eficiencia de esas instituciones, reforzado por la percepción de su impotencia o complicidad, según los casos, ante el proceso paralelo de profundización a escala global de la crisis del Estado social y del modelo de integración antes dominante a través del empleo estable.

Lo que ya es incuestionable es que estos movimientos están estableciendo una nueva relación entre lo social, lo político y lo cultural y, lo que es más importante, han obligado a modificar la "agenda" política y mediática de los estrategas de los grandes poderes transnacionales, cuya retórica ha tenido que ir cambiando a medida que esos movi- mientos se han hecho más visibles y han logrado una autolegitimación ética y politica ante amplios sectores de la opinión pública. Su acento en la defensa de "lo común", de "los bienes comunes" frente a los procesos de privatización de recursos básicos para satisfacer las necesidades de la mayoría de la población, se ha convertido en una de las principales señas de identidad de este movimiento, especialmente si nos referimos a países periféricos y semiperiféricos, como en América Latina y Asia.

En ese sentido se puede sostener que muchas redes de estos movimientos, desde su propia diversidad, estarían reconstruyendo un "meta-relato" global, en unos casos antineoliberal y en otros anticapitalista y abiertamente favorable a la reinvención de utopías emancipatorias. De ahí que lleguen a ser percibidos como partes de un nuevo "sujeto en proceso" que podría tomar el relevo, en cierto modo, de un viejo movimiento obrero cuya crisis de centralidad como sujeto antagonista no ha hecho más que acentuarse durante la segunda mitad del siglo XX.

Debido al nuevo contexto de la "globalización" y a los efectos que ha tenido en la desestructuración de muchas sociedades, la composición de estos movimientos se ha hecho mucho más diversa que la de los "nuevos movimientos sociales". Si extendemos el análisis más allá del ámbito europeo, una forma quizás simplista pero muy gráfica para describir a sus principales soportes sería la que nos ofrecen Pedro Ibarra y Salvador Martí (2003) cuando los ubican entre los "indígenas, indigentes e indigestos": o sea, los pueblos indígenas, partes del "precariado" en el Norte y sectores de capas medias o trabajadores sociales con capital crítico. No obstante, faltaría mencionar también al campesinado, cuyo protagonismo a través de las organizaciones 
que se coordinan en Vía Campesina es relevante en países como Brasil, México o el Sudeste asiático. Son esa heterogeneidad social y, al mismo tiempo, su convergencia en una identidad colectiva de proyecto común las que pueden explicar la receptividad que han tenido propuestas de autodefinición como "multitud", recuperando asi un viejo concepto spinozista que, a su vez, sirvió para describir aquellos motines de subsistencia que se dieron en Gran Bretaña durante el siglo XVIII y que se constituyeron en precedente del movimiento obrero emergente en aquel entonces. Esta propuesta es sin duda discutible pero sí describe un momento histórico de transición en el que esa multitud global se mueve más por convicciones, razones y valores que por intereses de clase o de grupo social determinado.

En cuanto al repertorio de acciones de estos movimientos, éste se ha caracterizado por una combinación de viejas formas (manifestaciones...) con otras relativamente nuevas (bloqueos al acceso a centros oficiales, acampadas, pasacalles, creación de centros de convergencia alternativos en torno a las "Cumbres" oficiales) y otras completamente nuevas ("pirateria" electrónica, boicot electrónico a determinadas instituciones y empresas transnacionales, SMS...), todo ello con la intención de "colarse en el espectáculo que esas mismas "Cumbres" querían ofrecer ante los televidentes de todo el mundo y respetando al mismo tiempo la propia diversidad del movimiento en sus formas de expresión pública y lúdica a través de "bloques de afinidad". La opción ampliamente mayoritaria a favor de la resistencia civil activa y no violenta también ha sido una demostración de la voluntad de difundir un nuevo tipo de cultura que busca denunciar las distintas formas de violencia realmente dominantes -estructural, simbólica, política, social, urbana...-, con el fin de oponer a las mismas la necesidad de alcanzar una paz basada en la justicia en todas las esferas de la vida.

Se puede sostener, por tanto, que los discursos, recursos organizativos, referentes simbólicos y agendas de trabajo que suelen caracterizar a todo movimiento social se dan también en este "movimiento de movimientos" y garantizan su continuidad, con mayor razón cuando el marco de injusticia global que denuncian prosigue y no ha sufrido cambios sustanciales, salvo parcialmente en determinados ámbitos nacional-estatales, como ocurre en América Latina, o locales.

A este respecto tiene interés mencionar el pronóstico que hace Sidney Tarrow (2005), un veterano estudioso de los movimientos sociales, al referirse al nuevo activismo transnacional. Desde su punto de vista, éste será episódico y contradictorio pero tendrá un impacto más visible que en el pasado en las politicas en el ámbito estatal (quizás en este caso el ejemplo más reciente y visible sea el de Francia y la deslegitimación que han ido sufriendo determinadas políticas y propuestas calificadas por estos movimientos como neoliberales). Pero, simultáneamente, los activistas transnacionales encontrarán en las decisiones que tomen las instituciones y tratados internacionales un "arrecife de coral" en el que puedan seguir presionando y protestando y llegar a formar coaliciones nacionales-globales capaces de obtener éxitos significativos en los próximos años. De ahí que su conclusión final sea que "el activismo transnacional no se parece a una marejada de la historia sino, más bien, a una serie de olas que alcanzan la playa internacional, retirándose repetidamente a los mares internos pero dejando cambios crecientes en la costa”.

Todo lo anterior no significa negar que la mayoría de las redes de estos movi- 
mientos se encuentra ante la necesidad de alcanzar un mayor anclaje social en los sectores sociales más directamente afectados por las politicas neoliberales. Es aquí donde tropiezan con las dificultades que crea la creciente fragilización de las relaciones sociales entre esos mismos sectores a los que aspiran a dirigirse, debido a la segmentación y fragmentación crecientes en que se encuentran y a las limitaciones que tienen esas mismas redes para asentarse en unos espacios territoriales y urbanos en los que en muchos casos se reproduce una segregación social y étnica. Sólo el apoyo en los medios alternativos de información y comunicación a través de internet constituye un recurso capaz de compensar esas debilidades manteniendo, al menos, una comunidad virtual de discurso y de protesta de carácter transversal, capaz de crear sinergias y reducir los costes de la movilización. Obviamente, todo esto no sustituye la imprescindible interacción cara a cara entre las minorías de activistas articulados en red de redes antes, durante y después de las fases de mayor visibilidad de estos movimientos. Esto es más necesario si cabe dada la concepción de democracia participativa, directa y horizontal que es compartida por la mayoría de estas redes y que les exige, por tanto, su práctica coherente a la hora de deliberar y buscar el mayor consenso posible para seguir trabajando en común.

\section{BIBLIOGRAFÍA}

Alonso, L.E. (1994). Crisis y transformación de los nuevos movimientos sociales en un entorno posfordista. En P. del Castillo (Ed.): Comportamiento politico y electoral (577-606). Madrid: CIS

Calle, Angel (2006). Los nuevos movimientos globales. Madrid: Editorial Popular.

Giddens, A. (1993). Consecuencias de la modernidad. Madrid: Alianza Universidad (Orig.: 1990).

Gómez Gil, G. (2004). Las ONG en la globalización. Barcelona: Icaria.

Ibarra, P., Goma, R. y Martí, S. (2002). Los nuevos movimientos sociales. El estado de la cuestión. En P. Ibarra, S. Martí y R. Goma (Eds.): Creadores de democracia radical. Movimientos sociales y redes de politicas públicas. Barcelona: Icaria.
Ibarra, P. y Martí, S. (2003). Los movimientos antiglobalización. La Consulta Social para la Abolición de la Deuda Externa. En M. J. Funes y R. Adell (Eds.): Movimientos sociales: Cambio social y participación. Madrid: UNED.

Inglehart, R. (1977). The Silent Revolution. Changing Values and Political Styles Among Western Publics. Princeton: Princeton University.

Inglehart, R. (1991). El cambio cultural en las sociedades avanzadas. Madrid: CIS (Orig.: 1990).

Lebowitz, M. (2005). Más allá de El Capital. Madrid: Akal (Orig.: 1992).

Melucci, A. (1986). Movimenti sociali e sistema político. Milan: Franco Angelli. 
Offe, C. (1988). Partidos políticos y nuevos movi mientos sociales. Madrid: Sistema.

Pastor, Jaime (2002). Qué son los movimientos antiglobalización. Barcelona: RBA-Integral.

Putnam, R. D., Pharr, S. J. y Dalton, R. (2000). Introduction. En Pharr, S.J. y Putnam, R.D. (Eds.) : Disaffected Democracies. What's Troubling Trilateral Democracies. Princeton: Princeton University Press.

Riechmann, J. (1991). ¿Problemas con los frenos de emergencia? Movimientos ecologistas y partidos verdes en Holanda, Alemania y Francia. Madrid: Revolución.
Tarrow, S. (1998). El poder en movimiento. Los movimientos sociales, la acción colectiva y la politica. Madrid: Alianza Universidad (Orig.: 1994).

Tarrow, S. (2005). The New Transnational Activism. Cambridge: Cambridge University Press.

Tilly, Ch. (1984). Social Movements and National Politics. En Ch. Bright y S. Harding (Eds.): Statemaking and Social Movements (297-317). Michigan: University of Michigan.

Wallerstein, I. (1993). 1968: revolución en el sistema-mundo. Viento Sur (9), 97-110. 